\title{
Development and Evaluation of Sucrose Free Herbal Orally Disintegrating Tablets of Ginger
}

\section{Achhra $\mathrm{CV}^{1}$ and Pawar $\mathrm{HA}^{2^{\star}}$}

${ }^{1}$ Principal K. M. Kundnani Pharmacy Polytechnic, Smt. CHM College Campus, Ulhasnagar-421003, Maharashtra, India ${ }^{2}$ Dr. L. H. Hiranandani College of Pharmacy, Ulhasnagar-421003, Maharashtra, India

\begin{abstract}
The objective of the present study was to develop orally disintegrating tablets of dry ginger powder with sugar free ingredients. In the present research work, orally disintegrating tablets of ginger were prepared by wet granulation method. A total of eight formulations were prepared with different compositions. The formulated tablets were evaluated for post-compression parameters. FTIR spectroscopic studies revealed that there was no interaction between the dry ginger powder and other excipients used in the formulations. The disintegration time of the optimized formulation was less than $30 \mathrm{sec}$. The in vitro release study of optimized formulation showed more than $90 \%$ drug release at the end of $10 \mathrm{~min}$. The optimized formulation B8 showed good in vitro and in vivo antimicrobial activity against Gram positive bacteria Staphylococcus aureus, Corynebacterium diphtheriae, Streptococcus pyogenes and Gram-negative bacteria Klebsiella pneumoniae. The formulation B8 was found to be stable for one month under accelerated stability condition.
\end{abstract}

Keywords: Ginger; Mannitol; Aspartame; Tablets; Disintegration time; Antimicrobial activity

\section{Introduction}

Drug delivery systems are becoming increasingly sophisticated as pharmaceutical scientists acquire a better understanding of the physicochemical and biochemical parameters pertinent to their performance. Over the past three decades, orally disintegrating tablets (ODTs) have gained considerable attention as a preferred alternative to conventional tablets and capsules due to better patient compliance. ODTs are solid dosage forms containing medicinal substances which disintegrate rapidly, usually in a matter of seconds, when placed on the tongue.

The US Food and Drug Administration Centre for Drug Evaluation and Research (CDER) defines, in the 'Orange Book', an ODT as "a solid dosage form containing medicinal substances, which disintegrates rapidly, usually within a matter of seconds, when placed upon the tongue" [1]. The significance of these dosage forms is highlighted by the adoption of the term, "Orodispersible Tablet", by the European Pharmacopoeia which describes it as a tablet that can be placed in oral cavity where it disperses rapidly before swallowing [2].

Today in the world of pharmacy around $90 \%$ of the tablets manufactured are ingested orally [3]. Administration of drugs through oral route is the most common and the easiest way to administer a drug. However, paediatric, geriatric and bedridden patient shows inconvenience swallowing conventional tablets or capsules due to difficulties in swallowing with lesser amounts of water with the medication, unable to tolerate the taste of many drugs when formulated as liquid dosage forms, resulting in poor patient compliance. The rationalised approach in case of medication leads to the development of orally disintegrating tablets particularly in case of local mouth infections, mouth sores, inflammations and throat infections with the scope of local delivery of medicament in the mouth itself or even for intended systemic delivery of medicament through buccal/sublingual absorption thereby bypassing hepatic route. Upon disintegration, they dissolve slowly in the mouth and release their ingredients in the process and therefore, do not have lag time as required for the disintegration of tablets before absorption from stomach [4].
Ginger is used as food and medicine and as an aromatic, carminative, expectorant in cough and cold, antiemetic and digestive and as common herbal remedy [5]. It is also useful in sore throat and other infectious diseases. Plenty of Candy lozenges containing ginger are available in the market but have high content of sucrose. Diabetics are reluctant to use sucrose containing formulations and hence it was decided to develop sucrose free compressed ODTs containing ginger. Mannitol, being metabolically inert in humans, can be used as sugar substitute. In the current study, orally disintegrating tablets containing dry ginger powder were formulated using mannitol.

\section{Materials and Methods}

\section{Materials}

Dry ginger powder of edible grade was procured from Anand Industries, Ulhasnagar, India. Microcrystalline cellulose (MCC) and polyvinyl pyrrolidine (PVP K-30) were obtained from Dr. Reddy's Laboratories, Hyderabad, India. Mannitol, aspartame and citric acid were purchased from SD Fine Chemicals Ltd., Mumbai, India. Menthol and purified talc powder were purchased from Molychem laboratories, Mumbai, India. Isopropyl alcohol was purchased from E. Merck, Mumbai, India. Peppermint oil, camphor, thymol, methyl salicylate, magnesium stearate and aerosil were procured from Alpha chemicals laboratory, India. Other chemicals and reagents used in the study were of analytical reagent grade.

*Corresponding author: Harshal Ashok Pawar, Dr. L. H. Hiranandani College of Pharmacy, Ulhasnagar-421003, Maharashtra, India, Tel: +91-8097148638; E-mail: harshal.dlhhcop@gmail.com

Received November 21, 2017; Accepted December 04, 2017; Published December 11, 2017

Citation: Achhra CV, Pawar HA (2017) Development and Evaluation of Sucrose Free Herbal Orally Disintegrating Tablets of Ginger. J Bioanal Biomed 9: 288-293. doi:10.4172/1948-593X.1000195

Copyright: () 2017 Achhra CV, et al. This is an open-access article distributed under the terms of the Creative Commons Attribution License, which permits unrestricted use, distribution, and reproduction in any medium, provided the original author and source are credited. 


\section{Preformulation studies}

Identification of dry ginger powder and excipients: Dry ginger powder and excipients used in the study were identified by organoleptic evaluation. Organoleptic characteristics of the dry ginger powder and excipients were matched with the specifications laid down in the standard reference book. Gingerol content of the dry ginger powder was determined by reported UV-spectroscopic method. Ginger powder and all excipients were subjected to tests for identity and purity as prescribed in respective monographs for each sample in Indian Pharmacopoeia 2010 and compliance was noted before using them in the formulation. Since intended formulation was supposed to be sucrose free, all raw materials used to prepare formulation were subjected to Molisch's test, Benedict's test, Fehling's test and Tollen's reagent test for presence of sugars [6].

Flow property of dry ginger powder: The dry ginger powder was evaluated for bulk density, tapped density; Carr's Index, Hausner's Ratio and angle of repose in order to find its flow characteristics and was found to exhibit good flow property.

Drug-Excipient compatibility studies: The compatibility studies provide the scheme for the drug combination with excipients in the fabrication of the dosage form. The study was carried out to establish that the therapeutically active drug has not undergone any changes after it has been subjected to processing steps during formulation of ODT. The drug (dry ginger powder) and excipients in optimized formulation were checked for their compatibility by Fourier Transform Infrared Spectroscopy (FT-IR Spectrophotometer Affinity 1, Shimadzu, Japan) using potassium bromide $(\mathrm{KBr})$ pellet method. The characteristic peaks were recorded. Depending on the favourable compatibility test results, the formulation was designed and the formulation aspects were initiated [7].

The drug and excipients compatibility studies were performed by preparing physical mixture of drug and excipients in different ratios $(1: 1,1: 1,1: 5,1: 10)$ and subjecting samples at $50^{\circ} \mathrm{C}$ for one month. At the end of one month, samples were observed for physical change, if any and FTIR spectra of all the samples were taken.

Testing of raw materials for presence of pathogens: All raw materials used in preparation of ODTs were tested for presence of pathogens. The Samples were streaked on respective plate medium and checked for growth of specific organism as per the procedure laid down in Indian Pharmacopoeia 2010. Incubation temperature for Bacteria was $37^{\circ} \mathrm{C}$ and for Yeast and Mold was $25^{\circ} \mathrm{C}-30^{\circ} \mathrm{C}$.

Preparation of granules (granulation) of dry ginger powder: ODT containing $300 \mathrm{mg}$ dry ginger powder was prepared by wet granulation method. All ingredients used in the formulation were passed through 60 \#. Accurately weighed quantities of menthol, peppermint oil, camphor and thymol were mixed in a beaker to get a eutectic mixture. This mixture was added to measured quantity of methyl salicylate. The entire mixture was added to measured quantity of Isopropyl alcohol containing weighed quantity of polyvinyl pyrrolidine (PVP K-30) and mixed well. The resultant liquid mixture (A) was used for granulation. Dry ginger powder, mannitol, microcrystalline cellulose, aspartame and citric acid were weighed and sifted through sieve ( 80 \#) and were thoroughly mixed to form dry mixture. The liquid mixture (A) prepared above was added to the dry mixture to get dough. The dough thus obtained was sieved through sieve no. 12. The obtained wet granules were dried in hot air oven at $50^{\circ} \mathrm{C}$ for one hour. Dried granules were passed through sieve no. 20 and retained on sieve no. 40 . Magnesium stearate, purified talc and aerosil were weighed and mixed properly and added extra granularly in the above sifted dried granules. The final blend of granules was mixed thoroughly for $2 \mathrm{~min}$ to $3 \mathrm{~min}$ in polybag and evaluated for various pre-compression parameters. The composition of the preliminary trial batches taken for the development of ODT of dry ginger powder is depicted in Table 1.

Pre-compression evaluation of granules: The flow properties of the prepared granules were characterized in terms of angle of repose, bulk density, tapped density, Carr's index and Hausner's ratio [8].

\begin{tabular}{|c|c|c|c|c|c|c|c|c|c|}
\hline \multirow{3}{*}{ Ingredients } & \multirow{3}{*}{$\begin{array}{c}\text { Role/ } \\
\text { Function }\end{array}$} & \multicolumn{8}{|c|}{ Batch numbers } \\
\hline & & B1 & B2 & B3 & B4 & B5 & B6 & B7 & B8 \\
\hline & & \multicolumn{8}{|c|}{ Quantity in mgs } \\
\hline Dry ginger powder & Active ingredient & 300 & 300 & 300 & 300 & 300 & 300 & 300 & 300 \\
\hline D-Mannitol & Sweetening agent & - & - & - & 175 & 175 & 370 & 360 & 350 \\
\hline Dibasic calcium phosphate & Diluent & 374 & 363 & 353 & 178 & 168 & - & - & - \\
\hline PVP K-30 (Polyvinyl pyrrolidine) & Binder & 11 & 11 & 11 & 11 & 11 & 11 & 11 & 11 \\
\hline Microcrystalline cellulose & Disintegrant & - & 10 & 20 & 10 & 20 & - & 10 & 20 \\
\hline Aspartame & Sweetening agent & - & - & - & 20 & 20 & 20 & 20 & 20 \\
\hline Citric acid & Pharmaceutical aid & 1 & 1 & 1 & 1 & 1 & 1 & 1 & 1 \\
\hline Menthol crystals & $\begin{array}{c}\text { Pharmaceutical aid (cooling } \\
\text { effect) }\end{array}$ & 1 & 1 & 1 & 1 & 1 & 1 & 1 & 1 \\
\hline Peppermint oil & Flavouring agent & - & - & - & - & - & $0.002 \mathrm{ml}$ & $0.002 \mathrm{ml}$ & $0.002 \mathrm{ml}$ \\
\hline Camphor & Pharmaceutical aid & 0.02 & 0.02 & 0.02 & 0.02 & 0.02 & 0.02 & 0.02 & 0.02 \\
\hline Thymol & Pharmaceutical aid & 0.02 & 0.02 & 0.02 & 0.02 & 0.02 & 0.02 & 0.02 & 0.02 \\
\hline Methyl salicylate & Fragrance & - & - & - & - & - & $0.1 \mathrm{ml}$ & $0.1 \mathrm{ml}$ & $0.1 \mathrm{ml}$ \\
\hline $\begin{array}{c}\text { IPA } \\
\text { (Isopropyl alcohol) }\end{array}$ & Vehicle & $\begin{array}{l}0.4 \\
\mathrm{ml}\end{array}$ & $0.4 \mathrm{ml}$ & $0.4 \mathrm{ml}$ & $0.4 \mathrm{ml}$ & $0.4 \mathrm{ml}$ & $0.4 \mathrm{ml}$ & $0.4 \mathrm{ml}$ & $0.4 \mathrm{ml}$ \\
\hline Magnesium stearate & Lubricant & 10 & 10 & 10 & 10 & 10 & 10 & 10 & 10 \\
\hline Purified talc & Lubricant & - & - & - & - & - & 5 & 5 & 5 \\
\hline Aerosil & Free flowing agent & - & - & - & - & - & 4 & 4 & 4 \\
\hline Strawberry flavour & Flavouring agent & 15 & 15 & 15 & 15 & 15 & - & - & - \\
\hline Saccharin & Sweetening agent & 10 & 10 & 10 & - & - & - & - & - \\
\hline
\end{tabular}

Table 1: Composition of various trial batches taken for development of ODT. 
For determination of angle of repose $(\theta)$, the granules were poured through the walls of a funnel, which was fixed at a position such that its lower tip was at a height of exactly $2.0 \mathrm{~cm}$ above hard surface. The granules were poured till the time when upper tip of the pile surface touched the lower tip of the funnel. The $\tan ^{-1}$ of the (height of the pile/ radius of the base) gave the angle of repose.

Granules were poured gently through a glass funnel into a graduated cylinder cut exactly to $10 \mathrm{ml}$ mark. Excess granules were removed using a spatula and the weight of the cylinder with granules required for filling the cylinder volume was calculated. The cylinder was then tapped from a height of $2.0 \mathrm{~cm}$ until the time when there was no more decrease in the volume. Bulk density $(\mathrm{Pb})$ and tapped density $(\mathrm{Pt})$ were calculated.

Hausner's ratio (HR) and Carr's index (IC) were calculated according to the two equations given below:

\section{$\mathrm{HR}=\mathrm{pt} / \mathrm{pb}$}

$\mathrm{IC}=(\mathrm{pt}-\mathrm{pb}) / \mathrm{pt} \times 100$

Preparation of ODT (Compression of granules): The granules obtained were compressed on a rotary tablet machine (Cadmach, Ahmedabad) using $15 \mathrm{~mm}$ standard flat punches. The compression force was adjusted to yield tablets with hardness of $4 \mathrm{~kg} / \mathrm{cm}^{2}$ and the average weight was controlled to $722 \mathrm{mg} \pm 5 \%$. Amongst eight batches prepared, batch B8 showed good results and acceptability and hence B8 was selected as an optimized formulation.

\section{Post compression evaluation of ODT:}

Physical characterisation: The appearance of tablets, its visual identity and overall elegance is essential for consumer acceptance. The formulated ODT's were evaluated for size, shape and organoleptic characters. The diameter and thickness of the ODT's was measured using micrometer. Twenty tablets were taken from each batch and average thickness and diameter was recorded [9].

Weight variation/Uniformity of weight: Twenty tablets of each batch were selected at random and weighed individually and collectively on a digital weighing balance. The weight of individual tablets was noted. Average weight was calculated and the individual weights were compared with the average weight. The weight of not more than two tablets must not deviate from the average weight by $\pm 5 \%[10]$.

Hardness: Hardness is a force required to break a tablet across the diameter. The hardness of a tablet is an indication of its strength. Hardness was measured using Monsanto Hardness tester by taking six tablets from each batch 10 . The values obtained were expressed in $\mathrm{Kg} / \mathrm{cm}^{2}$.

Friability: The friability of prepared tablets was measured using a Roche Friabilator [11]. Twenty pre-weighed tablets were rotated at $25 \mathrm{rpm}$ for $4 \mathrm{~min}$. The tablets were taken out and de-dusted and were reweighed and the percentage of weight loss was calculated.

Percentage friability $=[($ Initial Weight - Final Weight $) /$ Initial Weight $] \times 100$

Wetting time and water absorption ratio: A piece of tissue paper folded twice was kept in a Petri dish (Internal diameter: $5.5 \mathrm{~cm}$ ) containing $6 \mathrm{ml}$ of purified water. An ODT having a small amount of Rosaline dye powder on the upper surface was placed on the tissue paper. The time required to develop a red colour on the upper surface of the ODT was recorded as the wetting time $[10,12]$. The same procedure without Rosaline dye powder was followed for determining the water absorption ratio $\mathrm{R}$ which was determined according to the following equation.

$$
\mathrm{R}=[(\mathrm{Wa}-\mathrm{Wb}) / \mathrm{Wb}] \times 100
$$

Where, $\mathrm{Wb}$ and $\mathrm{Wa}$ were the weights of the ODTs before and after use.

Disintegration time: Disintegration time was determined in artificial saliva ( $\mathrm{pH} 5.8$ ) according to the USP method at $37 \pm 0.5^{\circ} \mathrm{C}$. The disintegration time of six individual tablets was recorded [13].

Drug content and Uniformity of dosage unit: Drug content in all formulations was estimated by UV-Spectrophotometric method. The uniformity of dosage unit was determined in each of twenty tablets spectrophotometrically using standard procedure [14]. Gingerol was used as a standard.

Moisture content: Moisture content of all the prepared formulations was determined by using Karl Fisher's apparatus (KA). Moisture content was determined using Mettler Karl Fischer Titrator. About $120 \mathrm{mg}$ of sample was weighed and added into the reagent solutions of the instrument, which was stirred and the tare weight was fed into the instrument. Then after certain duration of time the moisture content as $\% \mathrm{w} / \mathrm{w}$ was read on the monitor.

In vitro dissolution studies: The in vitro release of active drug component (Gingerol) from tablets was determined using USP dissolution testing apparatus type 2 (Paddle method; Electro Lab, Mumbai). The dissolution test was performed in $900 \mathrm{ml}$ of artificial saliva ( $\mathrm{pH} \mathrm{5.8)}$ at $50 \mathrm{rpm}$. The temperature of the dissolution medium was maintained at $37 \pm 0.5^{\circ} \mathrm{C}$ during the study. Aliquot's $(5 \mathrm{ml})$ were taken out from each dissolution vessel at different time intervals and the same volume was replaced with fresh dissolution medium. The samples were filtered through a $0.45 \mu$ membrane filter and diluted to suitable concentration with artificial saliva, $\mathrm{pH}$ 5.8. Absorbances of these solutions were determined spectroscopically. Cumulative percentage drug release was calculated using an equation obtained from a standard calibration curve of gingerol.

Stability study: The optimized formulation B8 was subjected to stability studies, by storing at $40^{\circ} \mathrm{C} \pm 2{ }^{\circ} \mathrm{C} / 75 \% \pm 5 \% \mathrm{RH}$ for a period of one month as per ICH guidelines $[15,16]$. The samples were evaluated for physical appearance, drug content, disintegration time and in vitro dissolution studies at the end of one month.

Evaluation of antimicrobial activity: The in vitro and in vivo antimicrobial potential of optimized formulation B8 was evaluated against Staphylococcus aureus, Corynebacterium diphtheriae, Streptococcus pyogenes, Klebsiella pneumoniae, Pseudomonas aeruginosa and Candida albican using the agar dick method. Inhibition of growth of micro-organisms was noted and the minimum inhibitory concentration was found out.

\section{Results and Discussion}

Ginger powder was found to be of edible grade and all excipients used in the study were found to meet the Pharmacopoeial specifications as mentioned in Indian Pharmacopoeia 2010. Dry ginger powder showed good flow property. The entire ingredient used in the formulation showed absence of sucrose and pathogenic micro-organisms.

The physical mixture of drug and excipients showed no significant change (NSC) in organoleptic characters at the end of one month at $50^{\circ} \mathrm{C}$. The results of physical observations of compatibility samples are depicted in Table 2. 
The FTIR spectrum of ginger powder and the optimized formulation B8 is depicted in Figures 1 and 2 respectively. All the major peaks of ginger were seen in FTIR spectrum of optimized formulation. The results of drug excipient compatibility study using FTIR indicated that there was no chemical interaction between drug and excipients used in the development of formulation.

The angle of repose indicates qualitative and quantitative assessment of internal cohesive and frictional force under low levels of external loading as might be applied in mixing and tableting. The results of micrometrics properties were found to be within satisfactory limits. All the prepared granules exhibited good flow

\begin{tabular}{|c|c|c|}
\hline \multirow[t]{2}{*}{ Ingredients } & \multirow[t]{2}{*}{ Ratio } & $\begin{array}{c}\text { At the end of one } \\
\text { month }\end{array}$ \\
\hline & & $\left(\right.$ At $\left.50^{\circ} \mathrm{C}\right)$ \\
\hline Dry ginger powder & - & NSC \\
\hline Dry ginger powder + Mannitol & $01: 10$ & NSC \\
\hline Dry ginger powder + Microcrystalline cellulose & $01: 10$ & NSC \\
\hline Dry ginger powder + PVP K-30 & 01:05 & NSC \\
\hline Dry ginger powder + Aspartame & 01:01 & NSC \\
\hline Dry ginger powder + Magnesium stearate & 01:01 & NSC \\
\hline SC: No significant change in physical/organolep & features & \\
\hline
\end{tabular}

Table 2: Drug-Excipients compatibility studies. property with an angle of repose value from 20 to 30 . The values obtained for Carr's index were within range (5\%-15\%) and for Hausner's ratio less than 1.25 indicating good compressibility of the granules. The results of post compression parameters are summarised in Tables $3(\mathrm{~A})$ and $3(\mathrm{~B})$.

All the formulations were subjected to physical- chemical evaluations like weight variation, thickness, hardness, friability, drug content, disintegration test and wetting time were carried out in order to assess the suitability of the formulations with respect to the dosage form and intended therapeutic purpose. The average weight of each formulation was within acceptable range. None of the tablet was falling outside weight variation limit of $\pm 5 \%$. The hardness of each formulation was evaluated and found between $4 \mathrm{~kg} / \mathrm{cm}^{2}$ to $4.4 \mathrm{~kg} / \mathrm{cm}^{2}$. The thickness of ODT was almost uniform in all the formulations and was found to be in the range of $3.0 \mathrm{~mm}$ to $3.28 \mathrm{~mm}$. Friability was in the range of $0.15 \%$ to $0.99 \%$. Friability test of all the prepared ODTs were satisfactory with value less than $1 \%$.

The ODT of optimized batch B8 showed smooth surface with no cracks when inspected using magnifying glass (5X and $10 \mathrm{X})$. The ODTs were light greyish to pale yellow coloured with mint odour and aromatic fragrance. The tastes of the ODTs were sweet with mild pungent taste of ginger and acceptable elegance.
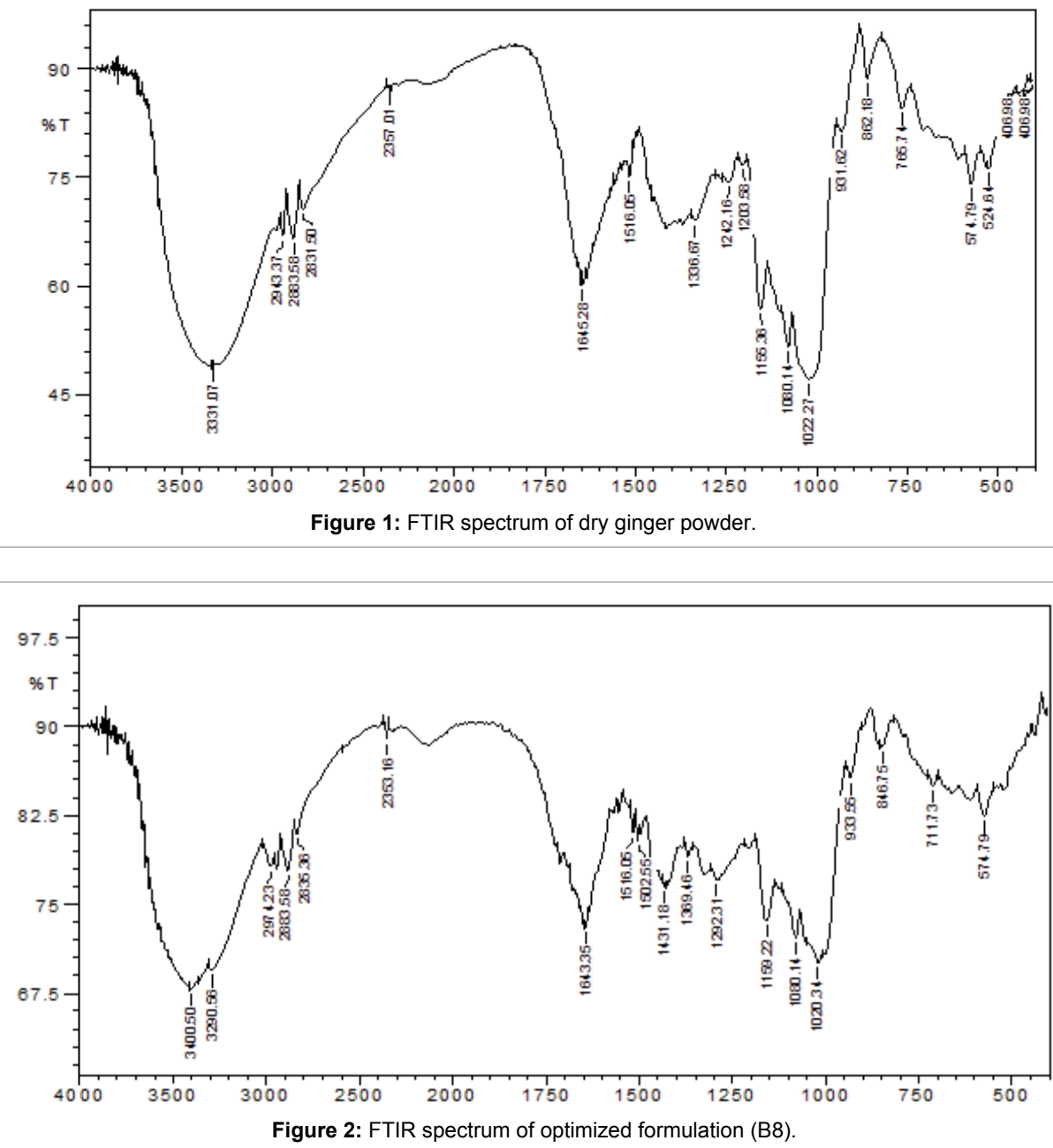


\begin{tabular}{|c|c|c|c|c|c|}
\hline Formula & $\begin{array}{c}\text { Average } \\
\text { weight }(\mathrm{mg})\end{array}$ & $\begin{array}{l}\text { Thickness } \\
\text { (mm) }\end{array}$ & $\begin{array}{l}\text { Diameter } \\
(\mathrm{mm})\end{array}$ & $\begin{array}{c}\text { Hardness } \\
\left(\mathbf{k g} / \mathrm{cm}^{2}\right)\end{array}$ & $\begin{array}{c}\text { Friability } \\
(\%)\end{array}$ \\
\hline B1 & $743.44 \pm 0.12$ & $3.01 \pm 0.0005$ & $14.95 \pm 0.17$ & $4.2 \pm 0.17$ & 0.99 \\
\hline B2 & $733.94 \pm 0.23$ & $3.28 \pm 0.0012$ & $15.02 \pm 0.02$ & $4.0 \pm 0.12$ & 0.39 \\
\hline B3 & $735.94 \pm 0.12$ & $3.20 \pm 0.0031$ & $15.03 \pm 0.01$ & $4.4 \pm 0.14$ & 0.28 \\
\hline B4 & $744.94 \pm 0.01$ & $3.10 \pm 0.0034$ & $14.98 \pm 0.02$ & $4.2 \pm 0.02$ & 0.20 \\
\hline B5 & $737.44 \pm 0.25$ & $3.15 \pm 0.0051$ & $14.99 \pm 0.01$ & $4.2 \pm 0.15$ & 0.16 \\
\hline B6 & $722.94 \pm 0.14$ & $3.25 \pm 0.0012$ & $15.12 \pm 0.01$ & $4.1 \pm 0.10$ & 0.15 \\
\hline B7 & $719.44 \pm 0.28$ & $3.18 \pm 0.0005$ & $15.22 \pm 0.01$ & $4.1 \pm 0.01$ & 0.49 \\
\hline B8 & $722.04 \pm 0.12$ & $3.0 \pm 0.0005$ & $15.00 \pm 0.01$ & $4.0 \pm 0.01$ & 0.19 \\
\hline
\end{tabular}

Table 3 (A): Results of post compression parameters of formulation B1-B8

\begin{tabular}{|c|c|c|c|}
\hline Formula & $\begin{array}{c}\text { Disintegration time } \\
(\mathbf{s e c})\end{array}$ & $\begin{array}{c}\text { Moisture content } \\
\mathbf{( w / w )}\end{array}$ & Assay (\%) \\
\hline B1 & $65 \pm 2$ & $1.92 \pm 0.05$ & $101.4 \pm 0.03$ \\
\hline B2 & $62 \pm 3$ & $1.90 \pm 0.09$ & $98.7 \pm 0.01$ \\
\hline B3 & $50 \pm 2$ & $1.90 \pm 0.01$ & $98.0 \pm 0.1$ \\
\hline B4 & $42 \pm 4$ & $1.84 \pm 0.17$ & $100.5 \pm 0.18$ \\
\hline B5 & $36 \pm 1$ & $1.73 \pm 0.05$ & $99.2 \pm 0.01$ \\
\hline B6 & $38 \pm 3$ & $1.71 \pm 0.5$ & $99.3 \pm 0.03$ \\
\hline B7 & $33 \pm 1$ & $1.73 \pm 0.02$ & $99.0 \pm 0.5$ \\
\hline B8 & $24 \pm 1$ & $1.75 \pm 0.02$ & $99.0 \pm 0.5$ \\
\hline
\end{tabular}

Table 3 (B): Results of post compression parameters of formulation B1-B8.

Wetting time is used as an indicator from the ease of tablet disintegration in buccal cavity. Wetting time of the optimized batch B8 was in the range of $15 \mathrm{sec}$ to $32 \mathrm{sec}$ and the absorption ratio was from 95.22 to 103.14. The tablets of formulation B8 were disintegrated within $30 \mathrm{sec}$.

The drug content of the prepared tablets was in the acceptable range and the correlation of variation was found to be less than $0.010 \%$ indicating uniformity of dosage unit. Drug content was found to be $98.0 \%$ to $101.4 \%$. Moisture content values were found is within range of $1.70 \% \mathrm{w} / \mathrm{w}$ to $1.95 \% \mathrm{w} / \mathrm{w}$.

The results of in vitro drug release of different formulations (B1B8) prepared are summarised in Table 4.

In vitro drug release profile for all formulations were carried out by using artificial saliva ( $\mathrm{pH} \mathrm{5.8)} \mathrm{as} \mathrm{dissolution} \mathrm{medium} \mathrm{for} 30 \mathrm{~min}$. It has been observed that the formulation $\mathrm{B} 8$ shows rapid drug release (i.e. more than $91 \%$ within $10 \mathrm{~min}$ ) as compared to other formulations. Hence, formulation B8 was considered as optimized formulation.

The results of stability study of optimized formulation at accelerated conditions are summarised in Table 5.

No significant changes in various parameters of optimized formulation B8 were observed in stability studies carried under accelerated conditions for one month.

The optimized formulation B8 showed good antibacterial activity against Gram positive bacteria Staphylococcus aureus, Corynebacterium diphtheriae, Streptococcus pyogenes and Gram-negative bacteria Klebsiella pneumoniae. No effect was observed against Pseudomonas aeruginosa (Gram negative bacteria) and Candida albican (fungus). The MIC of the formulation was found to be $1 \%$ wherein it inhibits all the test pathogens.

The results of in vivo antimicrobial evaluation of ODT on human volunteers are summarized in Table 6 . An average initial microbial count of $1480 \mathrm{CFU} / \mathrm{ml}$ was recorded from all the 8 volunteers. Each

\begin{tabular}{|c|c|c|c|c|c|c|c|c|}
\hline \multirow{2}{*}{$\begin{array}{c}\text { Sampling } \\
\text { time } \\
\text { (minutes) }\end{array}$} & \multicolumn{6}{|c|}{ Drug release profile (\% Cumulative drug release) } \\
\cline { 2 - 9 } & B1 & B2 & B3 & B4 & B5 & B6 & B7 & B8 \\
\hline \multirow{2}{*}{10} & $80 \pm$ & $82 \pm$ & $82 \pm$ & $85 \pm$ & $84 \pm$ & $86 \pm$ & $86 \pm$ & $91 \pm$ \\
& 0.90 & 0.52 & 0.43 & 0.24 & 0.23 & 0.28 & 0.90 & 0.90 \\
\hline \multirow{2}{*}{15} & $84 \pm$ & $88 \pm$ & $86 \pm$ & $89 \pm$ & $87 \pm$ & $90 \pm$ & $87 \pm$ & $94 \pm$ \\
& 0.82 & 0.85 & 0.56 & 0.51 & 0.29 & 0.35 & 0.82 & 0.82 \\
\hline \multirow{2}{*}{20} & $93 \pm$ & $91 \pm$ & $90 \pm$ & $92 \pm$ & $90 \pm$ & $92 \pm$ & $93 \pm$ & $98 \pm$ \\
& 0.28 & 0.68 & 0.76 & 0.73 & 0.40 & 0.73 & 0.54 & 0.54 \\
\hline \multirow{2}{*}{30} & $95 \pm$ & $93 \pm$ & $95 \pm$ & $94 \pm$ & $94 \pm$ & $96 \pm$ & $92 \pm$ & $98 \pm$ \\
& 0.58 & 0.72 & 0.23 & 0.04 & 0.20 & 0.26 & 0.29 & 0.29 \\
\hline
\end{tabular}

Table 4: In vitro release profiles study of different formulations.

\begin{tabular}{|c|c|c|}
\hline Parameter & Initial & $\begin{array}{c}\text { At the end of } \\
\text { one month }\end{array}$ \\
\hline Description & $\begin{array}{c}\text { Off white to pale } \\
\text { yellow, round shaped } \\
\text { flat tablets }\end{array}$ & No change \\
\hline Average weight (mg) & 722.04 & 723.11 \\
\hline Hardness $\left(\mathrm{kg} / \mathrm{cm}^{2}\right)$ & 4 & 3.99 \\
\hline Thickness (mm) & 3 & 3.01 \\
\hline Friability (\%) & 0.19 & 0.17 \\
\hline Water content by KA (\%w/w) & 1.73 & 1.63 \\
\hline Assay (\% label claim) & 99 & 98.2 \\
\hline Disintegration time (Seconds) & 24 & 27 \\
\hline Dissolution at the end of 30 min (\%) & 98 & 97 \\
\hline
\end{tabular}

Table 5: Results of stability study of optimized formulation B8 at the end of one month (Condition: $40^{\circ} \mathrm{C} \pm 2{ }^{\circ} \mathrm{C} / 75 \% \mathrm{RH} \pm 5 \% \mathrm{RH}$, Packing: HDPE bottle).

\begin{tabular}{|c|c|c|}
\hline Sample & $\begin{array}{c}\text { Average CFU/ } \\
\text { ml after 10 min }\end{array}$ & $\begin{array}{c}\text { Percentage change after 10 } \\
\text { min compared to Initial count }\end{array}$ \\
\hline Optimized formulation B8 & 826 & $44.18 \% \downarrow$ \\
\hline Control & 1773 & $19.79 \% \uparrow$ \\
\hline
\end{tabular}

Note: $\downarrow$ : Decrease in count; $\uparrow:$ Increase in count; CFU/ML: Colony Forming Units per $\mathrm{ml}$

Table 6: In vivo evaluation of antimicrobial activity of ODT formulation B8 in human volunteers.

set of two volunteers was administered with ginger ODT, while the last set of volunteers acted as control set. After $10 \mathrm{~min}$ of administration of ODT, the oral microbial flora was decreased by $44.18 \%$. The microbial count was reduced to $826 \mathrm{CFU} / \mathrm{ml}$ because of antimicrobial effect of ginger. In case of control set, the microbial count was increased considerably by $60.33 \%$ (Microbial count value: $1773 \mathrm{CFU} / \mathrm{ml}$ ) in 10 min due to absence of inhibitory drug. Thus, it can be concluded that the optimized ODT formulation B8 exhibits good in vivo antimicrobial activity.

\section{Conclusion}

ODTs of dry ginger powder can be prepared successfully by wet granulation method using sucrose free base. Plenty of lozenges containing ginger are available in the market but have high content of sucrose. Diabetics are unwilling to use sucrose containing formulations and the mannitol, being metabolically inert in humans; its ODTs may have voided acceptability among diabetics. These formulated herbal ODTs may provide a suitable alternative to commercially available lozenges especially for cough and cold, sore throat and other infections. Although chewable tablets have been on the market for some time, they are not the same as the new ODTs. Patients for whom chewing is difficult or painful can use these new tablets easily. ODTs can be used easily in children who have lost their primary teeth but do not have full use of their permanent teeth. This "patient-friendly dosage form" will thus provide rapid onset of action with increase in bioavailability. 
Citation: Achhra CV, Pawar HA (2017) Development and Evaluation of Sucrose Free Herbal Orally Disintegrating Tablets of Ginger. J Bioanal Biomed 9: 288-293. doi:10.4172/1948-593X.1000195

\section{Acknowledgement}

Authors are very much thankful to Late Dr. J. K. Lalla, Ex-Principal of Prin. K. M. Kundnani College of Pharmacy, Mumbai, Maharashtra, India for his continuous support, guidance and encouragement.

\section{References}

1. http://www.fda.gov

2. Pharmaeuropa (1998) European Directorate for Quality of Medicines. 10: 547.

3. Prashar D, Saklani S (2012) Formulation and evaluation of anthelmintic chewable tablets. IPS 2: 13-16.

4. Birader (2006) Formulation and evaluation of chewable tablets. Int J Pharmacy and Pharm Sci 2: 461-464.

5. Bhowmik D, Pankaj C, Tripathi KK, Chandira MR, Kumar KPS (2010) Zingiber officinale the herbal and traditional medicine and its therapeutically importance. Res J Pharmacognos Phytochem 2: 102-110.

6. Khandelwal KR (2007) Practical Pharmacognosy Techniques \& Experiments $18^{\text {th }}$ edn. Nirali Prakashan, Pune, India.

7. Kathiresan K, Vijin P, Moorthi C, Manavalan R (2010) Formulation and evaluation of loratadine chewable tablets. Res J Pharm Biological Chem Sci 1: 763-774.
8. Jaimini M, Rana AC, Tanwar YS (2007) Formulation and evaluation of famotidine floating tablets. Curr Drug Deliv 4: 51-55.

9. Aulton ME, Wells TI (1988) Pharmaceutics: The science of Dosage Form Design. $1^{\text {st }}$ edn. Churchill Livingstome, Vingstone, London, UK.

10. King RE, Schwartz JD (1990) Oral solid Dosage Forms. In: Remington's pharmaceutical sciences. $18^{\text {th }}$ edn. Mack publishing company. Easton, Pennsylvania, USA.

11. Indian Pharmacopoeia 2007 (2007) The Indian Pharmacopoeia. Ministry of Health and Family Welfare, Govt. of India, Controller of Publications, New Delh 2: $144,736,973,1377$.

12. Alanzi FK (2007) Evaluation of spray and freeze-dried excipient bases containing disintegration accelerators for formulation of metoclopramide orally disintegrating tablets. Saudi Pharm J 15: 105-119.

13. Abdelbary G, Eouani C, Prinderre P, Joachim J, Reynier JP, et al. (2004) Determination of the in vitro disintegration profile of rapidly disintegrating tablets and correlation with oral disintegration. Int J Pharm 292: 29-41.

14. USP 2007 (2007) United States pharmacopoeia. The official compendia of standards twin brook parkway. Rock Ville, Asian edition 3: 60-62.

15. www.fda.gov/guidance/ucm128204.pdf

16. www.ich.org./products/guidelines/quality.html 